Acta Universitatis Wratislaviensis No 3836

Anglica Wratislaviensia LVI, Wrocław 2018

DOI: 10.19195/0301-7966.56.19

Henk C. van Riemsdijk

ORCID: 0000-0003-2503-5480

Emeritus of Tilburg University

villasalmi@gmail.com

\title{
Mesovariation: A Review of Krzysztof Migdalski's Second Position Effects in the Syntax of Germanic and Slavic Languages, Wrocław: Wydawnictwo Uniwersytetu Wrocławskiego, 2016
}

\begin{abstract}
This review presents a concise overview of the main issues treated in Migdalski's book. Wackernagel's conjecture that there is a close relationship between the verb second phenomena in Germanic and the clitic second phenomena in Slavic must be closely related and must be the result of the same type of grammatical process is found to be only partly true, but also partly on the wrong track. This conclusion is reached on the basis of minute study of the relevant phenomena in a variety of Germanic and Slavic languages, both synchronically and diachronially. The result is an immensely rich exploration of second position phenomena in two major Indo-European language families.
\end{abstract}

Keywords: Germanic, information structure, macro-, micro- and meso-variation, prosody, Second Position Cliticization (CL2), Slavic, Verb Second (V2), Wackernagel

\section{Overview}

In this rich, well-researched, detailed and original study, Krzysztof Migdalski (henceforth KM) picks up an important conjecture by Jacob Wackernagel (1892). The conjecture was that there had to be a connection between the second position that the finite verb in many Germanic language must occupy and the fact that clitics in most Slavic languages must appear in the second position of the clause as well. KM's program for this book is to substantiate this conjecture. He explains that things, as they are so often, are more complicated, for example in that there are 
essentially two main types of clitics in Slavic that are quite distinct but do share the property of being second position clitics. He also investigates the merit of Wackernagel's hypothesis that these second position phenomena are the result of prosodic properties of the constructions in question and concludes that this hypothesis is erroneous and that second position phenomena are determined by syntactic principles (where the largely semantic labeling of positions in the left periphery of the clause in terms of notions such as Topic, Focus, Force and the like are included in the term 'syntax').

One of the striking properties of KM's book is that he systematically backs up his analysis of the present-day situation in the grammars of the Germanic and Slavic languages by relevant insights (many of them his own) into the diachronic development of the phenomena under consideration. Accordingly the book is quadripartite: chapter 1 deals with the synchronic properties of the verb second (V2) order in Germanic, chapter 2 investigates the history of the Germanic V2-phenomena all the way back to Old High German, Old Norse and even Gothic. Chapter 3 presents a detailed synchronic study of second position cliticization (henceforth CL2 ${ }^{1}$ ) in Slavic, and chapter 4 traces back the development of the modern situation all the way back to the oldest sources available for the investigation of the origin of CL2 in Slavic.

Clearly, then, the book offers a rich array of information, analyses and critical discussion of previous work in both Germanic and Slavic. Hence it addresses, primarily Germanicists and Slavicists, be they specialists of the modern Germanic languages or experts in the history of the Germanic languages. It is fair to say that the sociology of the field keeps some walls of considerable height up between these four specialisms. Your reviewer, for example, cannot claim to be anywhere near an authority on Slavic, be it syn- or diachronic, and furthermore he is largely a synchronic Germanicist with less than optimal knowledge of the history of the Germanic languages. Trying to surmount these walls in this book is as courageous and even daunting as it is stimulating and hopefully suggestive for future development of our field.

The terminology for research that investigates properties of more than one language, sometimes two, sometimes a few, sometimes many, sometimes related ones and sometimes non-related ones, has become rather confusing during the past few decades. Are we dealing here with a cross-linguistic approach, or should we call it variation linguistics, or is it typology? Rather popular terms, these days, are 'macro-variation'and 'micro-variation'. In general the term macro-variation

${ }^{1}$ I am using this abbreviation to refer to what KM consistently calls second position cliticization, presumably to make sure that both types of second position phenomena are covered: $2^{\text {nd }}$ position clitics and verb-adjacent clitics. 
is taken to be close to that of 'typology', or at least is taken to signify the study of relatively large numbers of languages that are not necessarily related. On the other hand, micro-variation focuses on relatively small numbers of languages (or varieties) that are related enough to yield insight into the factors that cause often minor differences between the languages or dialects under consideration. With this in mind, it is not so easy to decide which category the present study by KM falls in. The concentration on, say, V2 phenomena would presumably be termed micro-variation research. Similarly for CL2 phenomena. But bringing together Germanic V2 and Slavic CL2 in a single research project goes well beyond what is normally referred to as micro-variation. In this sense, Migdalski's program is groundbreaking and, I hope, groundbreaking enough to inspire many colleagues to set up equally ambitious research projects. I therefore felt that another term should be found, and in the absence of anything better, I am offering the term 'mesovariation' as used in the title of this review.

All this amounts to saying that KM's book is a gem. It collects, systematizes and analyzes a very considerable breadth of phenomena in terms of languages and language families and in terms of the synchronic and diachronic dimension. It is well written, very carefully researched, and groundbreaking enough to inspire readers who are neither Germanicists nor Slavicists and not necessarily focused on V2 and/ or CL2.

\section{Results chapter by chapter}

Presenting a complete summary of the book would be unfeasible for reasons of time and space. I will limit myself to a selective list of the most prominent issues that are discussed and what the outcome of KM's arguments is.

\section{a. Chapter 1: Properties of the V2 order}

A first issue that is dealt with is the question as to whether Wackernagel was correct in his assumption that V2 is due to prosodic factors, an opinion that was undoubtedly inspired more directly by the Slavic CL2 phenomena, as the clitics in question are very light phonetically reduced elements that tend to shift leftward and require a host. How this line of reasoning extends to V2 is not particularly clear. In many Germanic languages there are clitic-like elements, weak pronouns etc. that tend to be located in the V3 position. KM adduces evidence from the North Norwegian dialect of Troms $\varnothing$, where V2 placement is subject to prosodic restrictions having to do with the weight of the wh-element preceding the finite verb. KM shows that the argument is flawed and that the facts of the type found in the Tromsø dialect should rather be handled in terms of information structural considerations. More generally, it might be said that V2 is untypical for a syntactic phenomenon as it involves a 
movement that is not in any transparent sense triggered by some morphosyntactic feature or features. Personally I am a bit skeptical about this argument since many of the triggers that are posited as driving movement are either arbitrary, such as the EPP-features, or posited strictly by the postulated positions that are introduced when the left periphery of the clause is split up into a series of positions that may or may not be well motivated but bring with them the danger of a certain circularity in the argumentation.

Another argument that KM presents has to do with the notion of modality. Any account of V2 (or, for that matter, CL2) would involve tearing down at least part of the wall between syntax and phonology. This is perfectly true, but it is much less clear that a 'syntactic' analysis in terms of a more or less finely grained left periphery with intermediate projections whose feature makeup relies on notions such as topic, focus, force and the like is not blurring the dividing line between semantics and syntax.

This being said, a host of important observations, analyses, discussions of pros and cons of the most prominent proposals of how to deal with $\mathrm{V} 2$ is presented and critically examined. Anyone interested in this complex matter should read this chapter. He or she will be enlightened by the wealth of knowledge presented in it. Again, presenting a detailed summary is not feasible, therefore I limit myself to a few more or less unrelated observations that occurred to me while reading the chapter.

Den Besten's (1989) elegant and simple proposal was that V2 uniquely targets $\mathrm{C}^{0}$ as the landing site for $\mathrm{V} 2$. MK argues quite successfully that this analysis cannot be maintained and that $\mathrm{T}^{0}$ is also a possible landing site. In particular, it is argued that embedded clauses without an overt complementizer and with V2 in German lack a CP shell altogether and that, hence, the landing site of the finite verb must be $\mathrm{T}^{0}$. This consideration makes a lot of sense in many ways, but I would like to point out that such V2 complement clauses can also occur with contrastive left dislocation (CLD). Examples would be (1) and (2).

(1) Der Hans hat gesagt, den Peter den habe er schon lange nicht gesehen the Hans has said the Peter that-one have he already long not seen 'Hans said that Peter he had not seen him for a long time.'

(2) Er hat gesagt, am Sonntag dann komme er ganz bestimmt. he has said on Sunday then comes he most certainly

'He said on Sunday he would most certainly come then'

On the standard assumption that the left dislocated DP or PP is followed by a CP in which the ('contrastive') d-pronoun occupies the Spec,C position, there is no reason why the tensed verb should not be in $\mathrm{C}^{0} .{ }^{2}$ The question arises then if,

${ }^{2}$ Note that it is quite unclear what node dominates the LD construction: [??? $\mathrm{DP} / \mathrm{PP} \mathrm{i}_{\mathrm{i}}[\mathrm{CP}$ [Spec,CP $\mathrm{d}-$ word $\left.\left._{\mathrm{i}}\right] \mathrm{C}^{0}\right]$ ]. This is true for unembedded and embedded LD-constructions alike. 
perhaps, all complementizerless V2 complement clauses could be assumed to project to (at least) CP. And if that were the right way to go, then it could lead to a more parsimonious use of information-structural functional heads in the left periphery. On the other hand, it is clear that every analysis I know of needs a T-projection, hence there would always be a (minimally?) split system consisting of $\mathrm{C}^{0}$ and $\mathrm{T}^{0}$, very much in line with what KM proposes.

\section{b. Chapter 2: The diachrony of V2 in Germanic}

This chapter discusses in minute detail the origin and development of V2 phenomena in the Germanic languages. The most important analyses of the available data and the ensuing proposals are presented. The data provide additional evidence for the non-uniform conception of verb placement, that is, the idea presented in chapter 1 to the effect that the finite verb moves either to $\mathrm{C}^{0}$ or to some lower functional head, be it $\mathrm{T}^{0}$ or Force $\left(\mathrm{F}^{0}\right)$. What has clearly remained constant is the fact that V2 affects only tensed verbs and that, therefore, $\mathrm{T}^{0}$ is the prime candidate for the role of trigger of $\mathrm{V} 2$.

A particularly important issue concerns the question as to the restrictions imposed on V2 in some but not all Germanic languages. It is well-known that, by and large, V2 in Modern English is only possible in operator contexts (WH, NEG, etc.). KM shows that this restriction is also found in Gothic and in Old English, whereas Old Norse and Old High German lack this restriction and have highly regular V2 grammars, as the author puts it. This issue is of particular importance in that it also plays a crucial role in the syntax of CL2 in the Slavic languages in chapters 3 and 4 .

\section{c. Chapter 3: Properties of the CL2 order}

To start with, of course, there are a number of striking differences between Germanic V2 and Slavic CL2. First, V2 is limited to (tensed) verbs, while CL2 affects prosodically reduced elements (clitics) of different syntactic categories including verbal, nominal and operator clitics as well as clitics that serve to determine the illocutionary force of the sentence. Second, the different types of clitics can differ in their 'choice' of hosts. This, KM argues, leads us to conclude that the position occupied by second position clitics in Slavic is also non-uniform, just as was observed in the case of Germanic V2. Third, CL2 is not limited to root and root-like contexts unlike V2, which is largely limited to root contexts. ${ }^{3}$

3 The boundaries are actually somewhat fuzzy. First, as we have noted, there are complementizerless complement clauses that require V2, but there are also non-embedded main clauses that fail to trigger V2. Some notorious examples are given in (i) and (ii): 
On the other hand, there is also at least one remarkable similarity. In some of the Slavic languages, CL2 is limited to operator contexts while other Slavic languages do not have this restriction.

Interestingly, KM shows that the distinction between $2^{\text {nd }}$ position clitics and verb adjacent clitics is structural. $2^{\text {nd }}$ position clitics do not target a uniform head. Instead each clitic type raises to a separate specifier position above VP. On the other hand, verb-adjacent clitics all adjoin to one and the same designated head, viz. $\mathrm{T}^{0}$. Another way of putting this is that verb adjacent clitics form a cluster (they behave like a constituent, they cannot be split), but that $2^{\text {nd }}$ position clitics do not form a cluster. These observations constitute an invitation to draw another connection between Slavic second position clitics on the one hand and verb clustering phenomena in some Germanic languages (in particular Dutch and German and their varieties). While KM does use the term Verb Raising, he uses this term to describe the raising of $\mathrm{V}$ to higher functional nodes such as $\mathrm{T}^{0}$. But this use of the term has been usurped from the rule that was proposed in the early and groundbreaking work by Evers (1975). In Evers' interpretation verb raising is an adjunction rule applying to verbal heads, thereby creating verb clusters. This is at least very suggestive. As clustering is a phenomenon found both in the syntax of clitics and in the syntax of verbs both in Germanic and in Slavic, one may wonder whether this is an accident or not. I would suggest that this could be a promising line of research to follow up on.

\section{d. Chapter 4: The diachrony of CL2}

This chapter again presents a complete and careful analysis of the properties of the different types of clitics found in Slavic. These properties and their differences are presented for the complete array of Slavic languages, and the development from the older stages to the present day patterns.

The observations in chapter 3 are confirmed by the diachronic findings. In particular, the establishment of the two major classes of cliticization, viz. V-adjacent cliticization vs. $2^{\text {nd }}$ position cliticization are shown to be firmly rooted in the history of the Slavic languages. The major differences from chapter 3 are found to be characteristic of many of the older varieties as well: V-adjacent clitics all adjoin to a single functional projection, mostly $\mathrm{T}^{0}$ and form a cluster, while $2^{\text {nd }}$ position

(i) Gelachen dat we hebben! (Dutch) laughed that we have 'Boy did we laugh!'

(ii) $\mathrm{Ob}$ er wohl heute noch kommt? (German) whether he possibly today still comes?

'Might he still come today?' 
clitics do not form a cluster but each clitic (type) has a separate designated functional head that it targets. ${ }^{4}$

The evidence presented stems from a remarkably broad set of constructions and principles which include clitic climbing, incorporation into negation, and the Person Case Constraint (PCC).

We have already noted earlier that the presence of tense plays an important role in the behavior of clitics in Slavic, just as it is a crucial factor in the case of V2 in Germanic. KM shows that tense marking is gradually lost in some of the Slavic languages, in particular in Russian and Polish. He shows that this development finds its origin in a gradual loss of the interdependence between tense and aspect. In Old Russian and Old Polish cliticization was dependent on the interdependency between tense marking and cliticization. But in these two languages tense marking gradually got lost, and as a result the former clitics became weak pronouns.

These are just a few of the ways in which the diachronic study of the processes in question elucidates and reinforces the findings established in the analysis of the contemporary situation in the grammars of the various modern Slavic languages.

\section{Conlusion and outlook}

KM's careful and thorough examination has left us with a rather tough heritage. Wackernagel's idea that there seems to be a deep and significant relation between V2 in Germanic and the second position behavior of clitics in the Slavic languages remains a very attractive goal to pursue, but working out all the detailed ins and outs of substantiating this idea inexorably leads to the conclusion that there is so much variation that it remains a great challenge to identify the common ground. The relevant considerations turn out to be so complex that it is even hard to summarize the main lines in KM's admirable book that have a direct bearing on the one big question: what unites Germanic V2 and Slavic CL2?

For Wackernagel, an important part of the answer was his conclusion that both V2 and CL2 are essentially prosodic in nature. In more modern terms, that they are not part of the syntax but post-syntactic. However, KM's book adduces plenty of evidence that argues against such a view. Instead, he presents ample evidence that what constitutes the essence of the mechanisms underlying V2 and CL2 is information structure. In particular a variety of factors having to do with illocutionary force. KM assumes, as do many generative syntacticians, that the relevant elements of information structure such as topic, focus and, in particular force are encoded in the syntactic structure by means of functional projections.

${ }^{4}$ One would probably have to say that even in the case of $2^{\text {nd }}$ position clitics there is a 'cluster' of some kind in that when there are several, it is the bunch of them that jointly constitute the second position, even if they do not constitute a joint constituent. In that sense, perhaps, we could talk about a span of clitics in the complex functional projection to which the notion of 'second' place applies. 
This being said, however, we are immediately confronted with the fact that V2 in Germanic and CL2 in Slavic are far from uniform. In Germanic, for example, V2 is general in many varieties such as German and Dutch, but it is limited to an operator triggered process of movement to the second position in English. Similarly, in Slavic we need to distinguish two main types of CL2, viz. operator triggered CL2 as opposed to general CL2. Furthermore, we also need to distinguish V-adjacent cliticization and general second position cliticization.

These findings do not, of course, imply a criticism. On the contrary, they cry out for ideas and answers. Why these subtypes of CL2 and V2 and not others? There is, in other words, a rich research program that KM saddles us with. On the other hand, we must ask ourselves if there is truly nothing that appears to be truly common between the two (sets of) constructions. At the somewhat lower level, we must, in any case, single out the fact that both V2 and CL2 have subtypes that are triggered by the presence of operators. But, as I read the situation, the main common factor is that the presence of tense morphology is a necessary condition for the presence of V2 or CL2 in a Germanic or Slavic language.

This formulation immediately suggests the question as to whether we find either V2 or CL2 in other languages, be it close to home or further away. One might think, for example, about the syntax of clitics (or weak pronouns) in German: they tend to move (and cluster) in a position immediately to the right of $\mathrm{C}^{0}$. They do not have to but they can and are often preferred in that position. If we then suppose that there is a link between German CL2 and the second position clitics in Slavic, the question immediately arises as to why Slavic does not appear to have any occurrences of V2. Apparently there are none, but answering the question why is far from trivial. Clearly, asking this type of questions would immediately take us quite far afield. We know that V2 does occur in many languages. Warlpiri is one and Vata is another one. Clearly, there is a lot more work to do.

Turning back now to the question of whether there are truly no common factors linking Germanic V2 and Slavic CL2. KM's conclusion, let me repeat it, is unequivocal: yes, there is one, the presence of tense morphology. Indeed, one of his most convincing pieces of evidence showing this is that Old Church Slavonic, Old Serbian and Old Polish had second position clitics but they were limited to a few operator clitics. Soon, however, tense morphology in these languages started declining. In particular the aorist and the imperfect were lost, and concomitantly pronominal clitics lost the property of verb adjacency and developed into weak pronouns.

What is remarkable about this major finding is that it is an argument based on the diachrony of the languages in question. Indeed, one of the many things we can learn from this book is to take the diachronic development of the languages under consideration into account whenever possible.

Krzysztof Migdalski's book is tough going, at times, especially for readers like myself with very limited knowledge about Slavic languages and little experience 
with historical linguistics, but the effort is fully worth it. There is a wealth of analytical insight and the basis for a very valuable research program. The book is therefore obligatory reading for people working on V-movement and on clitics, not only in Germanic and Slavic but well beyond. And most of all, this book shows that the time is ripe to start bridging the gap between micro-variation and macro-variation. We are entering the aera of meso-variation.

\section{References}

Besten, H.B. den. 1989. "On the Interaction of Root Transformations and Lexical Deletive rules." In: idem (ed.). Studies in west germanic syntax. Amsterdam: Rodopi. 14-100.

Evers, A. 1975. The Transformational Cycle in Dutch and German. University of Utrecht: Ph.D. Dissertation, Distributed by the Indiana University Linguistics Club.

Migdalski, K. 2016. Second Position Effects in the Syntax of Germanic and Slavic Languages. Wrocław: Wydawnictwo Uniwersytetu Wrocławskiego.

Wackernagel, J. 1892. "Über ein Gesetz der indogermanischen Wortstellung." Indogermanische Forschungen 1.333-436. 